\title{
Beer enrichment with biologically active hop compounds
}

\section{Lidia Protsenko ${ }^{1}$, Ruslan Rudyk ${ }^{1}$, Tetiana Hryniuk ${ }^{1}$, Aliona Vlasenko ${ }^{1}$, Alona Protsenko ${ }^{1}$, Svitlana Litvynchuk ${ }^{2}$, Olena Ovadenko ${ }^{2}$}

\author{
1 - Agricultural Polissia Institute of National Academy of Agrarian Sciences of Ukraine, \\ Zhytomyr, Ukraine \\ 2 - National University of Food Technologies, Kyiv, Ukraine
}

Keywords:

Hop

Beer

Xanthohumol

Beta-acids

Polyphenols

\section{Article history:}

Received

17.01.2018

Received in revised form 14.03.2018

Accepted

29.03.2018

\section{Corresponding author:}

Lidia Protsenko

E-mail:

lidiya.procenko@

ukr.net

DOI:

$10.24263 / 2304-$

974X-2018-7-1-7

\section{Abstract}

Introduction. The research was aimed at studying the influence of biologically active compounds of the Ukrainian hop varieties on beer quality indicators and peculiarities of their use in brewing.

Materials and methods. The research was focused on the aroma Slavyanka hop variety with a high beta-acid content and on the special Ruslan and Xantha hop varieties with an increased xanthohumol content, as well as on the beer made of them. To identify the amount and composition of bitter substances and xanthohumol in the hop plant, as well as the products of their transfer during brewing, the liquid chromatography (HPLC) was employed, while bitterness of the hopped wort and the final beer was controlled by the spectrophotometric methods.

Results and discussions. In beer enrichment with biologically active hop compounds, an optimal ratio of the fine aroma hops to the bitter ones, which ensures high beer quality, is as follows: $40 \%$ of the rated bitterness derived from alpha-acids were added with the special Ruslan and Xantha hop varieties, and 60\% were obtained through addition of fine aroma hop varieties with a high beta-fraction content. The suggested method of combined dosing of fine aroma hops and special hop varieties makes it possible to obtain up to $13.0-20.0 \mathrm{mg} / \mathrm{dm}^{3}$ of iso-alpha-acids in beer with further achievement of a $160.0-200.0 \mathrm{mg} / \mathrm{dm}^{3}$ content of polyphenolic compounds. This ensures higher colloid stability of the beer and a 15-20\% increase in the extent of applying bitter substances. In wort hopping, the use of the fine Slavyanka aroma hop variety, having a great amount of beta-acids and the best ratio of beta- to alpha-acids of $1.3: 1.8$ as a raw material contributes to producing compounds with pleasant, soft bitterness. Whereas the use of the Slavyanka hops with a low cohumulone content of alpha-acids (21.4\%) provides a reduced, up to $5.0-7.0 \mathrm{mg} / \mathrm{dm}^{3}$, isocohumulone content of beer, which improves the quality of bitterness. Meanwhile, the use of the special Ukrainian hop varieties, Ruslan and Xantha, with a content of xanthohumol up to $1.2 \%$ makes for the isoxanthohumol formation in beer in the range of $2.0-5.0 \mathrm{mg} / \mathrm{dm}^{3}$.

Conclusion. Combined use of the Slavyanka hop variety and the Ruslan and Xantha hops in the suggested ratio enriches the drink with biologically active hop compounds, thus improving its functionality. 


\section{Introduction}

The use of the hop plants in brewing is due to the presence of numerous substances, biologically active compounds, which impart biological stability to beer, contribute to its conservation and create the foam and a unique bouquet of taste and aroma properties. It is different hop varieties that are responsible for the peculiar characteristic aroma and taste of the beer [1-3]. Besides brewing, the hop plant is used in breadmaking, pharmacology, official and folk medicine. The major substances responsible for the hop cone biological activity are bitter and phenolic compounds, as well as the essential oil [4, 5]. Bitter substances are the most beneficial and specific constituents of the hop cones, which in this form are not available in other plants [2,6]. The most profound effect on the specific properties of beer is exerted by isomers of the starting bitter hop substances, which exist in minor amounts in its cones, but are formed on wort boiling with hop.

Alpha- and especially beta-acids inhibit the development of gram-positive and gramnegative bacteria, as well as acid-forming microorganisms [2], but have no effect on yeast development and vital activity. This is of great importance for the brewing technology since an optimal bitter substance content increases microbiological stability of the beer. Humulone, besides its antibiotic properties toward the bacterial microflora, hampers the growth of some harmful fungi.

The Japanese scientists have proven that $\beta$-acids inhibit the growth of the bacterium (Helicobacter pylori), which has invaded almost half of the population of the planet and causes onset of gastritis, as well as gastric and duodenal ulcer. The association between the presence of this bacterium and onset of gastric cancer has been proven [7].

Colupulone, the constituent of $\beta$-acids, is known to hamper the development of various microorganisms, including the pathogens, such as Staphylococcus aurers, Mycobacterium tuberculosis and Mycobacterium phei. As long ago as 1949, it was found out that $\alpha$ - and $\beta$ acids bring under adequate control the growth of tubercle bacilli [8]. Along with the antiseptic action, they also exert the sedative effect [9].

There is no doubt that taste and aroma of the beer made of various hop varieties also depends on different content of polyphenolic compounds. The polyphenolic hop compounds are the antioxidants, increasing the beer's recovering capacity and effecting taste stability. On boiling, they make for protein precipitation and formation of composite protein-polyphenolic complexes, the precipitation of which favors wort lightening, and thus prevents oxidation and losses of bitter hop substances. However, on prolonged boiling, high-molecular polyphenols cause unpleasant beer mouthfeel. So, the polyphenolic hop substances influence the beer taste and quality not on their own, but in a complex with bitter hop substances, proteins and amino acids.

Salach et al., when analyzing the hop quality dependency on the polyphenol content, noted that in the Czeck varieties, the latter is much higher than in the hop varieties of other countries. Thus, the polyphenol content of the Czeck Zhatetsky hop variety, noteworthy for the highest quality, comprises 5.2-5.9\%, whereas that of the American one is no more than $26 \%$. They considered a high polyphenol content of the Zhatetsky hop as its advantage over the other varieties. Contemporary scientists also claim that the best quality has the beer made of hop with about $5 \%$ of polyphenol $[10,11]$.

Among hop phenols, the unique compounds are available, such as prenylated flavonoids of the halcone and flavanone types. Previously, the prenylated flavonoids were treated somewhat meagerly in terms of either hop growing or their subsequent use in brewing. Only at the end of the last century $[12,13]$, the scientists became deeply involved in studying these substances due to their high biological activity. At present $[14,15]$, more 
than two tens of compounds belonging to the group of prenylated flavonoids have been revealed in the hop plant. The prenylated hop flavonoids exhibit an extremely wide spectrum of biological activity. They exhibit anticancer, phytoestrogenic, antioxidant and antiviral properties. In particular, xanthohumol is being studied now as a potential anticancer agent. Rather wide spectrum of antiviral activity of the prenylated hop flavonoids has been presented [16-22]. In the cell culture, the isoxanthohumol-enriched hop extracts moderately inhibit reproduction of the bovine viral diarrhea, which serves as a surrogated model of the human HCV, 2 HSV-2 and rhinovirus [23].

There has also been established an antioxidant activity of the prenylated flavonoids, which neutralize active radicals of oxygen and inhibit the processes of free radical oxygenation behind the development of cardiovascular diseases [24, 25]. Among halcones, the most important is xanthohumol. The xanthohumol content of different hop varieties immediately after harvesting ranges $0.2-1.1 \%$ of the weight $[7,9,24,25]$. As wort is boiled with hop, about $70 \%$ of xanthohumol undergo isomerization to form isoxanthohumol [26]. Of this amount, about $30 \%$ end up in beer. Isoxanthohumol also has a high anticancer potential.

Xanthohumol and isoxanthohumol, as expected, are the main compounds responsible for the positive human health consequences of beer in case of its moderate consumption [5, $17,27]$. In this context, the currently pressing problem in the world brewing practice is an increase of prenylated chalcone content of beer, as well as the development of brewing technologies for beer and hop extracts enriched with xanthohumol [17, 27].

\section{Materials and methods}

The research employed modern international physical and chemical methods to analyze bitter substances and xanthohumol of hops and hop extracts, as well as the products of their transfer in the process of brewing, namely: high-performance liquid chromatography (HPLC), spectrophotometry and methods of control harmonized with the procedures of European Brewing Convention [28, 29].

\section{Methods of studying quality indicators of hops}

The fine aroma Slavyanka hop variety with a high content of beta-acids, as well as the bitter Xantha and Ruslan hops with increased xanthohumol content were studied. The weight of the average sample used for identification and biochemical investigations was no less than $0.5 \mathrm{~kg}$ of the hop dry weight. The alpha-acids in the hop were identified by conductometry according to the EBC procedure 7.4 [28]. Bitter hop substances were extracted with using an organic solvent - methanol. The weight ratio of the hop cone to the extractant was 1:10. The HPLC was employed to measure the amount of $\alpha$ - and $\beta$-acids, as well as the cohumulone content of alpha-acids and the colupulone content of beta-acids, and also the content of isoxanthohumol. The chromatography was performed on the Ultimate 3000 chromatographer with the UV detector at the temperature of $35^{\circ} \mathrm{C}$. The 100 x $2.1 \mathrm{~mm}$ column filled with the Pinacle DB C18, $3 \mu \mathrm{m}$ was used. As a mobile phase, the solution of methanol, water and acetonitrile was used in the 38:24:38 ratio. The quantitative analysis of the bitter substance components was carried out by the international ICF-3 standard. 


\section{Method of beer sampling at the mini-brewery}

The experimental brewing with using the hop samples under study was carried out at the laboratory and at the mini-brewery of the Agricultural Polissya Institute of the National Academy of Agrarian Sciences of Ukraine, with a capacity of 100L of beer per cycle, which is rather an adequate prototype of an actual brewing conditions. In the brewing experiments, grain mash was prepared, saccharified and filtered according to the procedure accepted at this brewhouse. The wort was prepared of $100 \%$ barley malt. After wort had reached the full volume, it was boiled for 15 minutes, which led to coagulation of protein compounds. The hop products were added in three stages. The overall wort boiling with hop lasted 75 minutes.

\section{Methods of studying quality indicators of beer and wort}

Bitterness obtained during wort boiling with hops, as a result of extraction and isomerization of bitter hop substances, was measured on the spectrophotometer as per EBC 8.8 [28]. The method is based on determing optic density of the isooctane resulted from the extraction of bitter substances of the acidulated hopped wort or beer with isooctane $(2,2,4-$ trimethyl penthane), the wavelength being $275 \mathrm{~nm}$. The bitterness value expressed in the International Bitterness Units as per EBC, was estimated based on the optic density index.

The polyphenolic compound content of wort and beer was measured on the spectrophotometer as per EBC 8.11 and EBC 9.11 [28].

\section{Results and discussion}

To study the effect of biologically active hop compounds, in particular, beta-acids, polyphenols and xanthohumol, on quality indicators of wort and beer, a series of experiments was performed with using the Ukrainian hop varieties having an increased content of the above substances. The suggested method of wort preparation provides combined use of the fine aroma Slavyanka hop variety with a high content of beta-acids and hops of special Ruslan and Xantha varieties with an increased content of xanthohumol, as summarized in Table 1.

An alpha-acids content of the Slavyanka hop variety comprises 4.5-7.5\%, while that of beta-acids $-6.0-10.0 \%$. This variety contains a great amount of bitter substances and the best ratio of beta- to alpha-acids of $1.3: 1.8$. This pattern is the varietal attribute. One of the major features of beta-acids is their high antiseptic action, which is important for increasing beer stability on storage. A high farnesene content of the essential oil is responsible for soft and gentle aroma of wort and beer. The ratio of beta- to alpha-acids, as well as the amount and composition of the essential oil, combined with other components, make the fine aroma Slavyanka hop variety particularly valuable for brewery. The beer made of the Slavyanka hop variety exhibits high taste properties. It is characterized with soft and gentle bitterness. 
Quality indicators of the Slavyanka, Ruslan and Xantha hop varieties

\begin{tabular}{|c|c|c|c|}
\hline \multirow{2}{*}{ Quality indicators } & \multicolumn{3}{|c|}{ Hop variety } \\
\hline & Slavyanka & Ruslan & Xantha \\
\hline Bitter substances, $\%$ & $24.0-28.8$ & $27.0-32.6$ & $25.0-27.5$ \\
\hline$\alpha$-acid mass concentration, $\%$ & $4.5-7.5$ & $8.6-10.8$ & $8.2-11.1$ \\
\hline$\beta$-acid mass concentration, $\%$ & $6.0-10.0$ & $4.8-6.8$ & $5.1-6.0$ \\
\hline Cohumulone within $\alpha$-acids, $\%$ & $20-26$ & $30-35$ & $29-33$ \\
\hline Colupulone within $\beta$-acids, $\%$ & $38-46$ & $48-56$ & $49-57$ \\
\hline Beta- to alpha-acids ratio & $1.3-1.8$ & $0.7-0.9$ & $0.7-1.0$ \\
\hline $\begin{array}{l}\text { Essential oil, } \mathrm{mL} / 100 \mathrm{~g} \text { of the hop dry } \\
\text { weight, including }\end{array}$ & $1.0-2.0$ & $1.6-2.6$ & $0.7-1.2$ \\
\hline myrcene, $\%$ & $20-50$ & $40-50$ & $35-42$ \\
\hline caryophyllene, $\%$ & $7-8$ & $5-8$ & $10-12$ \\
\hline humulene, $\%$ & $14-16$ & $15-20$ & $20-30$ \\
\hline farnesene, $\%$ & $12-18$ & $<1.0$ & $<1.0$ \\
\hline selinene, $\%$ & $<1,0$ & $6.2-10.0$ & $<1.0$ \\
\hline Total polyphenols, $\%$ & $4.5-7.0$ & $4.0-6.5$ & $4.0-6.0$ \\
\hline Xanthohumol, \% & $0.4-0.5$ & $0.9-1.2$ & $0.8-1.1$ \\
\hline Brewer's assessment & $\begin{array}{c}\text { Excellent, } \\
\text { soft, gentle } \\
\text { bitterness and } \\
\text { sweet aroma }\end{array}$ & $\begin{array}{c}\text { Excellent, } \\
\text { noble } \\
\text { bitterness and } \\
\text { aroma }\end{array}$ & $\begin{array}{c}\text { Excellent, } \\
\text { evident and } \\
\text { balanced } \\
\text { bitterness and } \\
\text { aroma }\end{array}$ \\
\hline
\end{tabular}

In composition of bitter substances and essential oil, the Ruslan and Xantha hop varieties should be assigned to the bitter hop type. Increased cohumulone content of alphaacids (30-35\%) and the absence of farnesene in the essential oil would give beer harsh bitterness. Nevertheless, due to the high beta-acid content and ratio of beta- to alpha-acids (0.7-0.9) typical of the aroma hop varieties, the beer made of these varieties has excellent quality and evident, yet pleasant bitterness. Beta-acids improve the quality of bitterness, soften and smoothen it, thus balancing the overall bitterness of the beer. There is one more parameter which distinguishes advantageously these varieties among others. This is an increased content of biologically active compounds, namely: prenylated flavonoids, and first of all, xanthohumol. The content of this compound in the Ruslan and Xantha varieties is about $1 \%$.

In brewing technology, like in the process of alpha-acid isomerization to iso-alphaacids, wort hopping results in isomerization of $70 \%$ of xanthohumol to isoxanthohumol, which also exhibits anticancer properties (Figure 1). In this context, an increase in the isoxanthohumol content of beer and the development of brewing technologies for beer enrichment with xanthohumol are the urgent tasks of the world brewing. 

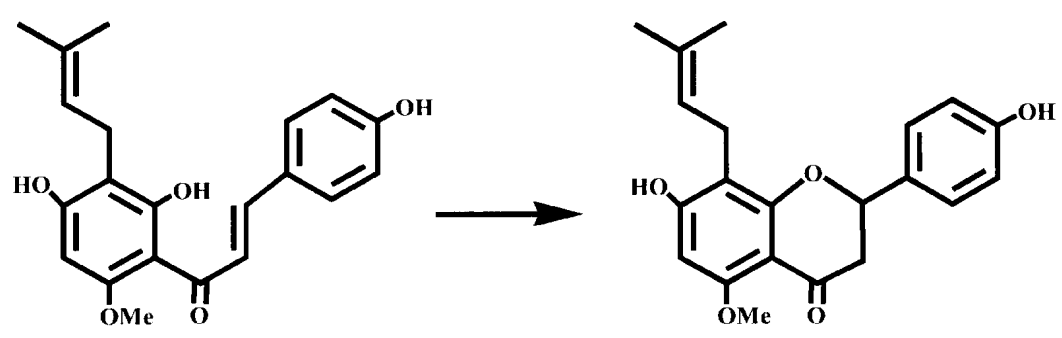

Hop xanthohumol Hop isoxanthohumol

Figure 1. Structural formulas of hop xanthohumol and beer isoxanthohumol

In-process testing of experimental brewing with the combined use of the fine aroma Slavyanka hop variety having a high beta-acid content and the special Ruslan and Xantha hop varieties having an increased xanthohumol content was carried out at the mini-brewery at the Agricultural Polissya Institute of NAAS of Ukraine. The brewing procedure was as follows. Grain mash was prepared, saccharified and filtered according to the procedure accepted at this brewhouse. After wort had reached the full volume, it was boiled for 15 minutes, which led to coagulation of the protein structure. The wort was boiled with hop for 75 minutes. The starting materials for wort hopping were the hop cones of the fine aroma Slavyanka variety and the bitter Ruslan and Xantha varieties with an increased xanthohumol content, as summarized in Table 2.

Quality indicators of hop samples

Table 2

\begin{tabular}{|c|c|c|c|c|}
\hline \multirow[t]{2}{*}{ № } & \multirow{2}{*}{ Hop quality indicators } & \multicolumn{3}{|c|}{ Test version (variety name) } \\
\hline & & Slavyanka & Ruslan & Xantha \\
\hline 1 & $\alpha$-acid content, $\%$ dry substances & 4.1 & 9.5 & 8.9 \\
\hline 2 & $\begin{array}{l}\text { Cohumulone within } \\
\alpha \text {-acids } \%\end{array}$ & 21.4 & 33.2 & 30.4 \\
\hline 3 & B-acid content, $\%$ dry substances & 5.8 & 6.9 & 7.2 \\
\hline 4 & $\begin{array}{l}\text { Colupulone within } \\
\alpha \text {-acids, } \%\end{array}$ & 42.8 & 54.3 & 53.8 \\
\hline 5 & $\beta / \alpha$-acids ratio & 1.41 & 0.73 & 0.81 \\
\hline 6 & $\begin{array}{l}\text { Isoxanthohumol content, \% dry } \\
\text { substances }\end{array}$ & 0.40 & 1.08 & 0.96 \\
\hline 7 & $\begin{array}{l}\text { Total polyphenol content, \% dry } \\
\text { substances }\end{array}$ & 5.6 & 4.3 & 5.1 \\
\hline
\end{tabular}


Experimental brewing was performed with these hop samples. Hop dosage adjusting in all wort samples was performed at $80 \mathrm{mg}$ of bitter substances per $1 \mathrm{dm}^{3}$ of wort. The amount of added alpha- and beta-acids, and xanthohumol, as well as the total amount of hop polyphenols, were determined by calculation, as presented in Table 3.

Table 3

Amount of bitter substances, xanthohumol and polyphenolic compounds added to wort with the Slavyanka, Puslan and Xantha hop varieties

\begin{tabular}{|c|l|c|c|c|c|}
\hline \multirow{2}{*}{ No } & \multirow{2}{*}{$\begin{array}{c}\text { Test version } \\
\text { (variety name) }\end{array}$} & \multicolumn{4}{|c|}{ Added with hop to $\mathbf{~ d m}^{\mathbf{3}}$ of wort, $\mathbf{~ m g / \mathbf { d m } ^ { \mathbf { 3 } }}$} \\
\cline { 3 - 6 } & & $\boldsymbol{\alpha}$-acids & B-acids & Xanthohumol & $\begin{array}{c}\text { Total } \\
\text { polyphenols }\end{array}$ \\
\hline 1 & Slavyanka & 80.0 & 113.2 & 6.8 & 110.0 \\
\hline 2 & Ruslan & 80.0 & 58.2 & 9.1 & 36.2 \\
\hline 3 & Xantha & 80.0 & 64.8 & 8.6 & 45.9 \\
\hline
\end{tabular}

As evident from the Table, on dosing hops of the varieties under study, the same amount of alpha-acids (about $80 \mathrm{mg} / \mathrm{dm}^{3}$ ) is added to $1 \mathrm{dm}^{3}$ of the wort, since the adjustment is based on their content. At the same time, when using the Slavyanka hop variety, twice as much alpha-acids and 2,4-3 times more polyphenolic compounds are added, as compared to the Ruslan and Xantha varieties. However, in case of the Ruslan and Xantha varieties, much more xanthohumol is added. Having analyzed different options of wort hopping, in using either a single fine and bitter hop variety or varietal blends, we have established an optimal ratio of the fine aroma to bitter hops, which ensures high quality of the beer, namely: $40 \%$ of the rated bitterness derived from alpha-acids were added with bitter hops, and the rest $60 \%$ - with hop pellets of the fine aroma Slavyanka variety. The rate of hopping can be changed with the formulation chosen and hopping conditions at a certain enterprise. Meanwhile, there are undoubted prerequisites for the adjustment of beer taste and aroma properties, beer enrichment with biologically active hop compounds, improvement of its quality and widening its assortment.

The technological solution of the suggested procedure is illustrated by the experiments presented.

\section{Experiment 1}

The starting raw materials for wort hopping were hop cones of the fine aroma Slavyanka and bitter Ruslan variety, containing an increased xanthohumol content. The hop products were added in three stages.

Wort hopping was performed at $80 \mathrm{mg}$ of bitter substances in $1 \mathrm{dm}^{3}$ of the wort, which constitutes $0.8 \mathrm{~g} / \mathrm{daL}$. Hop dosage adjusting during the experiments was performed according to the alpha-acid content as follows:

$$
H_{x}=\frac{R_{c} \times 10^{4}}{A K \times(100-W)}, .
$$

here $\mathrm{H}_{\mathrm{x}}$ is the hop rate $\mathrm{g} / \mathrm{daL}$;

$\mathrm{R}_{\mathrm{c}}$ - rate of bitter substances of the hop wort for this beer variety, $\mathrm{g} / \mathrm{daL}$;

AK - mass concentration of hop alpha-acids, $\%$ dry substances;

$\mathrm{W}-$ mass concentration of hop humidity, $\%$. 
An example of calculation of the amount of the Ruslan hop variety added to the wort is as follows:

$$
H_{x}=\frac{0.8 \times 10^{4} \times 0.4}{9.5 \times(100-10)}=3.74 \mathrm{~g} / \mathrm{daL} \text {. }
$$

In example of calculation of the amount of the Slavyanka hop variety added to the wort is as follows:

$$
H_{x}=\frac{0.8 \times 10^{4} \times 0.6}{4.1 \times(100-10)}=13.01 \mathrm{~g} / \mathrm{daL} \text {. }
$$

The first portion of hops, i.e. all the bitter Ruslan hops ( $40 \%$ of rated bitterness in terms of the alpha-acid content), were added 15 minutes after the start of wort boil. The rest $60 \%$ of bitterness were added with hop pellets of the fine aroma Slavyanka variety in two steps: $90 \%$ of the weight of the fine aroma Slavyanka hop variety were added 15 minutes after the addition of the first portion and $10 \%-10$ minutes before the hopping completion. The overall wort boiling with hop lasted 75 minutes. The beer made from a single fine aroma Slavyanka hop variety was used as a control.

The value of beer bitterness and the content of bitter substances measured by the HPLC method and spectrophotometry is given in Table 4.

\section{Composition of bitter substances of the beer samples}

Table 4

\begin{tabular}{|c|l|c|c|}
\hline \multirow{2}{*}{ № } & \multicolumn{1}{|c|}{ Beer quality indicators } & \multicolumn{2}{|c|}{ Test version } \\
\cline { 3 - 4 } & & Slavyanka 100 \% & $\begin{array}{c}\text { Slavyanka 60\% }+ \\
\text { Ruslan 40\% }\end{array}$ \\
\hline 1 & Beer bitterness, for EMS & 23.9 & 22.2 \\
\hline 2 & Iso-alpha-acid content, mg/dm & 14.2 \\
\hline 3 & $\begin{array}{l}\text { Isocohumulone within alpha-acids, } \\
\text { mg/dm }\end{array}$ & 16.8 & 7.0 \\
\hline 4 & $\begin{array}{l}\text { Isohumulone }+ \text { isoadhumulone } \\
\text { within alpha-acids, } \mathrm{mg} / \mathrm{dm}^{3}\end{array}$ & 11.5 & 7.2 \\
\hline 5 & Alpha-acid content, $\mathrm{mg} / \mathrm{dm}^{3}$ & 0.62 & 0.97 \\
\hline 6 & Isoxanthohumol content, $\mathrm{mg} / \mathrm{dm}^{3}$ & 3.71 & 4.51 \\
\hline 7 & Total polyphenol content, $\mathrm{mg} / \mathrm{dm}^{3}$ & 199.8 & 160.6 \\
\hline
\end{tabular}

As evident from Table 4, the beer samples differ in the amount and composition of bitter substances, isoxanthohumol and polyphenolic compounds. This is due to different content of all hop components and their ratio, and not just to alpha-acids. At the same time, of great importance is involvement of some hop compounds into creation of taste and aroma features of beer, as well as efficiency of their extraction and isomerisation in the wort hopping process. It should be noted that one adds much more xanthohumol to the second beer sample with the Ruslan hop variety. In the hopping process, xanthohumol undergoes 
isomerization to isoxanthohumol, contained in the given sample in abundance, thus enriching beer with xanthohumol and isoxanthohumol, and imparting some functionality to it.

The organoleptic quality assessment of the experimental beer samples (in scores) showed them to differ in taste and bitterness (Table 5). According to degustation, the beer samples had the clear hop aroma, however in the first sample it was softer. This sample also had the full balanced taste and gentle, smooth, and soft bitterness.

Table 5

\section{Mean score assessment of beer}

\begin{tabular}{|c|c|c|c|c|c|c|c|c|}
\hline \multirow[b]{3}{*}{ Test version } & \multicolumn{8}{|c|}{ Quality indicators } \\
\hline & \multirow[b]{2}{*}{ 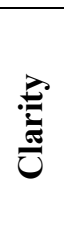 } & \multirow[b]{2}{*}{$\frac{\dot{\theta}}{\dot{\theta}}$} & \multirow[b]{2}{*}{ 疍 } & \multirow[b]{2}{*}{ 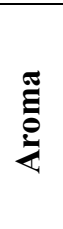 } & \multicolumn{2}{|c|}{ Flavor } & \multirow{2}{*}{ 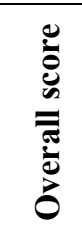 } & \multirow[b]{2}{*}{ 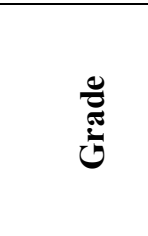 } \\
\hline & & & & & 总 & 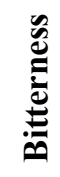 & & \\
\hline Slavyanka, $100 \%$ & 3 & 3 & 5 & 4.0 & 4.8 & 4.8 & 24.6 & Excellent \\
\hline $\begin{array}{c}\text { Slavyanka } 60 \%+ \\
\text { Ruslan } 40 \% \\
\end{array}$ & 3 & 3 & 5 & 3.9 & 4.7 & 4.7 & 24.3 & Excellent \\
\hline
\end{tabular}

The second sample differed from the first one in taste. Since alpha-acids of the Ruslan hop variety contained more cohumulone (Table 1 and 2), the beer made through adding this hop also had a higher isocohumulone content of iso-alpha-acids (Table 4). In the beer bitterness formation, a negative role is assigned to this fraction. However, beta-acids, introduced into the wort with the Slavyanka hop variety, improved the quality of bitterness, having softened and smoothened it, and thus made the whole bitterness balanced. Therefore, bitterness of the second sample was more evident and, at the same time, noble and pleasant. At the same time, the polyphenol content of beer comprises 160.6-199.8 $\mathrm{mg} / \mathrm{dm}^{3}$, which ensures not only high biological but also colloid stability of beer. An increased isoxanthohumol content of the second sample, in case of combined use of the Slavyanka and Ruslan hop varieties at the suggested ratio, enriches the drink with biologically active hop compounds, thus improving its functional properties.

\section{Experiment 2}

The procedure of wort preparation differs from the previous experiment in using the Xantha hop variety as a raw material, which also has an increased xanthohumol content. The hop was added in three stages.

Wort hopping was performed at $80 \mathrm{mg}$ of bitter substances in $1 \mathrm{dm}^{3}$ of wort, that is 0.8 $\mathrm{g} / \mathrm{daL}$. Hop rating during experiments required for wort hopping, was performed by the alpha-acid content, as follows

here $\mathrm{H}_{\mathrm{x}}$ is the hop rate $\mathrm{g} / \mathrm{daL}$;

$$
\mathrm{H}_{\mathrm{x}}=\frac{\mathrm{R}_{\mathrm{c}} \times 10^{4}}{\mathrm{AK} \times(100-\mathrm{W})},
$$


$\mathrm{R}_{\mathrm{c}}$ - rate of bitter substances of the hop wort for this beer variety, $\mathrm{g} / \mathrm{daL}$;

$\mathrm{AK}$ - mass concentration of hop alpha-acids, $\%$ dry substances;

$\mathrm{W}$ - mass concentration of hop humidity $\%$.

An example of calculation of the amount of the Xantha hop variety added was as follows:

$$
\mathrm{H}_{\mathrm{x}}=\frac{0.8 \times 10^{4} \times 0.4}{8.9 \times(100-10)}=4.00 \mathrm{~g} / \mathrm{daL}
$$

An example of calculation of the amount of the Slavyanka hop variety added to the wort is as follows:

$$
\mathrm{H}_{\mathrm{x}}=\frac{0.8 \times 10^{4} \times 0.6}{4.1 \times(100-10)}=13.01 \mathrm{~g} / \mathrm{daL} \text {. }
$$

The first portion of hops, i.e. all the bitter Ruslan hops $(40 \%$ of rated bitterness in terms of the alpha-acids content), were added 15 minutes after the start of wort boil. The rest $60 \%$ of bitterness were added with the hop pellets of the fine aroma Slavyanka variety in two steps: $90 \%$ of the weight of the fine aroma Slavyanka hop variety were added 15 minutes after the addition of the first portion and 10\%-10 minutes before the hopping completion. The total period was 75 minutes. The beer made from a single fine aroma Slavyanka hop variety was used as a control.

The value of beer bitterness and the content of bitter substances measured by the HPLC method and spectrophotometry is given in Table 6. As seen from Table 6, the samples differ in the amount and composition of bitter substances, isoxanthohumol and polyphenolic acids. This is due to the different content of all hop components in different hop varieties and their ratio and not just alpha-acids.

Bitter substance content of the beer samples

Table 6

\begin{tabular}{|c|l|c|c|}
\hline \multirow{2}{*}{ No. } & \multicolumn{1}{|c|}{ Beer quality parameters } & \multicolumn{2}{|c|}{ Test version } \\
\cline { 3 - 4 } & \multicolumn{1}{|c|}{$\begin{array}{c}\text { Slavyanka } \\
\mathbf{1 0 0} \%\end{array}$} & $\begin{array}{c}\text { Slavyanka 60\% + } \\
\text { Ruslan 40 \% }\end{array}$ \\
\hline 1 & Beer bitterness, units of EBC & 23.9 & 22.8 \\
\hline 2 & Iso-alpha-acid content, $\mathrm{mg} / \mathrm{dm}^{3}$ & 16.8 & 14.0 \\
\hline 3 & $\begin{array}{l}\text { Iso-cohumulone within alpha-acids, } \\
\text { mg/dm }\end{array}$ & 5.3 & 6.1 \\
\hline 4 & $\begin{array}{l}\text { Iso-humulone }+ \text { iso-adhumulone within } \\
\text { alpha-acids, } \mathrm{mg} / \mathrm{dm}^{3}\end{array}$ & 11.5 & 7.9 \\
\hline 5 & Alpha-acid content, $\mathrm{mg} / \mathrm{dm}^{3}$ & 0.62 & 1.03 \\
\hline 6 & Iso-xanthohumol content, $\mathrm{mg} / \mathrm{dm}^{3}$ & 3.71 & 4.67 \\
\hline 7 & Total polyphenol content, $\mathrm{mg} / \mathrm{dm}^{3}$ & 199.8 & 163.1 \\
\hline
\end{tabular}


It should be noted that one adds much more xanthohumol to the second sample with the Xantha hop variety. In the hopping process xanthohumol undergoes isomerisation to isoxanthohumol, contained in the given sample is abundance, thus enriching beer with xanthohumol and imparting some functionality to it. The score beer assessment is given in Table 7.

Table 7

Mean score degustation assessment of beer

\begin{tabular}{|c|c|c|c|c|c|c|c|c|}
\hline \multirow[b]{3}{*}{ Test version } & \multicolumn{8}{|c|}{ Quality parameters } \\
\hline & \multirow[b]{2}{*}{ 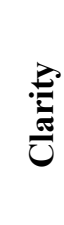 } & \multirow[b]{2}{*}{$\frac{\dot{\theta}}{\dot{\theta}}$} & \multirow[b]{2}{*}{ 胥 } & \multirow[b]{2}{*}{ 离 } & \multicolumn{2}{|c|}{ Flavor } & \multirow[b]{2}{*}{ 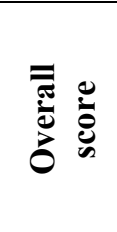 } & \multirow[b]{2}{*}{ } \\
\hline & & & & & 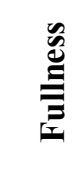 & & & \\
\hline Slavyanka $100 \%$ & 3 & 3 & 5 & 4.0 & 4.8 & 4.8 & 24.6 & Excellent \\
\hline $\begin{array}{l}\text { Slavyanka } 60 \%+ \\
\text { Xantha } 40 \%\end{array}$ & 3 & 3 & 5 & 3.8 & 4.8 & 4.8 & 24.4 & Excellent \\
\hline
\end{tabular}

Both beer samples had the clear hop aroma, but in the first sample it was softer due to farnesene, contained in the essential oil of the Slavyanka. This sample also had the full balanced taste and soft, gentle and smooth bitterness. The beer of the second sample had full harmonic taste and pleasant balanced and evident bitterness. At the same time, the polyphenol content of beer is $163.1 \mathrm{mg} / \mathrm{dm}^{3}$, which ensures not only high biological but also colloid stability of beer.

An increased isoxanthohumol content of the second beer sample, in case of the combined use of the Slavyanka and Xantha hop varieties as a raw material in the suggested ratio, enriches the drink with biologically active hop compounds, thus increasing its functionality.

For comparison, the physico-chemical parameters of the beer samples under study were determined. As seen from Table 8, the combined use of the Slavyanka and special Ruslan and Xantha hop pellets did not change physico-chemical parameters of the beer but enriched the beer with biologically active hop compounds, thus increasing its functionality.

Physical and chemical parameters of the beer samples under study

Table 8

\begin{tabular}{|l|c|c|c|}
\hline \multirow{2}{*}{ Beer quality parameters } & \multicolumn{2}{|c|}{ Test version (beer variety) } \\
\cline { 2 - 4 } & $\begin{array}{c}\text { Slavyanka } \\
\text { (control) }\end{array}$ & $\begin{array}{c}\text { Slavyanka+ } \\
\text { Ruslan }\end{array}$ & $\begin{array}{c}\text { Slavyanka + } \\
\text { Xantha }\end{array}$ \\
\hline Alcohol mass concentration, \% & 3.59 & 3.63 & 3.58 \\
\hline $\begin{array}{l}\text { Mass concentration of dry substances } \\
\text { in the starting wort, \% }\end{array}$ & 11.47 & 11.40 & 11.49 \\
\hline $\begin{array}{l}\text { Acidity, } \mathrm{cm}^{3} 1 \mathrm{~mole} / \mathrm{dm}^{3} \text { solution of } \\
\text { sodium hydroxide per } 100 \mathrm{~cm}^{3} \text { of beer }\end{array}$ & 1.8 & 1.7 & 1.7 \\
\hline $\begin{array}{l}\text { Color, } \mathrm{cm}^{3} 0.1 \mathrm{~mole}_{\mathrm{dm}}^{3} \text { of the iodine } \\
\text { solution per } 100 \mathrm{~cm}^{3} \text { of water }\end{array}$ & 0.8 & 0.8 & 0.8 \\
\hline
\end{tabular}


Having analyzed different versions of wort hopping, when using either a single fine aroma and bitter hop variety or the varietal blend, the suggested optimal ratio of aroma to bitter hops, ensuring high quality of beer, was confirmed namely: $40 \%$ of rated bitterness derived from alpha-acids were added with bitter hops, and the rest $60 \%$ - with the fine aroma Slavyanka hop variety. The hopping rate can be changed with the formulation chosen and the hopping conditions at a certain enterprise.

The above research resulted in the developed of a beer model with an optimal content of bitter substances, polyphenols, isomers of alpha-acids, xanthohumol and isoxanthohumol.

Application of the suggested brewing procedure enables the following technical result:

-wort hopping with using the Slavyanka hop variety, having a great amount of betaacids and the best ratio of beta- to alpha-acids of 1.3:1.8 as a raw material results in the formation of the compounds with pleasant soft bitterness;

-due to beta-acids, high antiseptic action is ensured, which exhibits a beneficial effect upon beer stability on storage;

-soft gentle aroma is imparted to the beer due to farnesene within the essential oil of the Slavyanka hop;

-the Slavyanka hop polyphenols, along with their bitter substances, in contrast to the polyphenols of malt and barley, are particularly responsible for fullness and clearness of the drink taste, and also act directly on the stability of foam and beer on storage, when interacting with high molecular wort proteins and forming composite complexes, which, when precipitate, improve the lightening of wort and beer;

-low isocohumulone content of beer is ensured due to the low cohumulone content of alpha-acids $(21.4 \%)$ of the Slavyanka hop variety;

-the presence of biologically active compounds - prenylated flavonoids, exhibiting an extremely wide spectrum of biological activity and revealing anticancer, antimicrobial, anti-inflammatory and antiviral properties, being also natural antioxidants, due to the use of the Ruslan and Xantha hop varieties on beer hopping;

-the presence of isoxanthohumol, also exhibiting the anticancer properties in beer, is due to mainly the Ruslan and Xantha varieties.

An increased isoxanthohumol content of beer, in case of combined use of the Slavyanka hop varieties with those of Ruslan and Xantha in the ratio suggested enriches the drink with biologically active hop compounds, thus improving its functionality.

The suggested dosing procedure favors adjustment of optimal varietal hop blending, as well as the products of its processing with ensuring the best values of bitterness and its quality at minimal hop consumption.

\section{Conclusions}

Combined dosage adjustment of fine aroma hops and those of special varieties according to the procedure suggested makes it possible to obtain up to $13.0-20.0 \mathrm{mg} / \mathrm{dm}^{3}$ iso-alpha-acids in beer, including isocohumulone up to $5.0-7.0 \mathrm{mg} / \mathrm{dm}^{3}$, with further achievement of polyphenolic compound contemt of beer in the range of 160.0-200.0 $\mathrm{mg} / \mathrm{dm}^{3}$ and isoxanthohumol within $2.0-5.0 \mathrm{mg} / \mathrm{dm}^{3}$. At the same time, the conditions are formed for beer enrichment with biologically active hop compounds due to the use of special Ukrainian varieties with an increased content of beta-acids, polyphenolic compounds and xanthohumol. 


\section{References}

1. Narziß L. (2005), Abriß der Bierbrauerei. 7th ed., Wiley-VCH, Weinheim, pp. 163170.

2. Lyashenko N.I. (2002), Hops and hop products вiochemistry, Polissia, Zhytomyr.

3. Biendl M., Pinzl C. (2007), Arzneipflanze Hopfen. Deutsches Hopfenmuseum Wolnzach, Wolnzach.

4. Danila A.O., Gatea F. and Radu G.L. (2011), Polyphenol composition and antioxidant activity of selected medicinal herbs, Chemistry of Natural Compounds, 47(1), pp. 2226.

5. Żołnierczyk AK, Mączka WK, Grabarczyk M, Wińska K, Woźniak E, Anioł M (2015), Isoxanthohumol - biologically active hop flavonoid, Fitoterapia, 103(71), p. 82.

6. Hanke S. (2010), Untersuchungen zum Einfluss der Hopfungstechnologie auf die Geschmacksstabilität und Harmonie untergäriger Biere, Technische Universität München, Freising.

7. Lyashenko N.I., Mykhajlov M.G. (2010), Curative potential of hop and beer, Agropromyslove vyrobnytstvo Polissja: Zbirnyk naukovykh prats', 3, pp. 50-54.

8. Stevens J.F., Taylor A.W., Clawson J.E. (1999), Fate of xanthohumol and related prenylfiavonoids from hops to beer, Journal Agricultural Food Chemistry, 47, pp. 2421-2428.

9. Fukao T., Sawada H., Ohta Y. (2000), Combined effect of hop resins and sodium hexametaphosphate against certain strains of Escherichia coli, J. Food Prot., 63(6), pp. 735-740.

10. Pavlovič V., Pavlovič M., Čerenak A., Košir I.J., Čeh B., Rozman Č., Turk J., Pazek K., Krofta K., Gregorič G. (2012), Environment and weather influence on quality and market value of hops, Plant Soil Environ, 58, pp. 155-160.

11. Srečec S., Zechner-Krpan V., Marag S., Špoljarić I., Mršić G. (2011), Morphogenesis, volume and number of hop (Humulus lupulus L.), glandular trichomes and their influence on alpha-acids accumulationin fresh bracts of hop cones, Acta Bot. Croat, 70, pp. $1-8$.

12. Stevens J.F., Miranda C.L., Buhler D.R. (1998), Chemistry and biology of hop flavonoids, Am. Soc. Brew. Chem, 56(4), pp. 136-145.

13. Miranda C. L., Stevens J.F. [et al.] (2000), Antioxidant and prooxidant action of prenylated and nonprenylated chalcones and flavanones in vitro, Agric. Food Chem., 48, p. 3876.

14. Magalhães PJ, Carvalho DO, Cruz JM, Guido LF, Barros AA (2009), Fundamentals and health benefits of xanthohumol, a natural product derived from hops and beer, Nat. Prod. Commun., 4(5), pp. 591-610.

15. Protsenko Lidiya, Litvynchuk Svitlana (2017), Features of using hops and $\mathrm{CO}_{2}$-extract in brewing, Ukrainian food journal, 6(1), pp. 77-84., DOI: 10.24263/2304-974X2017-6-1-9

16. Strathmann J., Klimo K., Sauer S.W., Okun J.G., Prehn J.H.M. and Gerhäuser C. (2010), Xanthohumol-induced transient superoxide anion radical formation triggers cancer cells into apoptosis via a mitochondria-mediated mechanism, FASEB Journal, 24(8), pp. 2938-2950.

17. Ferk F., Huber W.W., Filipič M. et al. (2010), Xanthohumol, a prenylated flavonoid contained in beer, prevents the induction of preneoplastic lesions and DNA damage in liver and colon induced by the heterocyclic aromatic amine amino-3-methyl- 
imidazo[4,5-f]quinoline (IQ), Mutation Research - Fundamental and Molecular Mechanisms of Mutagenesis, 691, 1-2, pp. 17-22.

18. Monteiro R., Calhau C., Silva A.O.E. et al. (2008), Xanthohumol inhibits inflammatory factor production and angiogenesis in breast cancer xenografts, Journal of Cellular Biochemistry, 104(5), pp. 1699-1707.

19. Xiu-Li Zhang, Yong-Dong Zhang, Tao Wang, Hong-Yun Guo, Qi-Ming Liu and HaiXiang Su (2014), Evaluation on Antioxidant Effect of Xanthohumol by Different Antioxidant Capacity Analytical Methods, Journal of Chemistry, Article ID 249485, DOI: $10.1155 / 2014 / 249485$.

20. Zamzow D.R., Elias V., Legette L.C., Choi J., Stevens J.F., Magnusson K.R. (2014), Xanthohumol improved cognitive flexibility in young mice. Behav. Brain Res., 275(1), p. 10.

21. Warnakulasuriya S.N. Ziaullah, Vasantha Rupasinghe H.P. (2014), Long chain fatty acid acylated derivatives of quercetin-3-O-glukoside as antioxidants to prevent lipid oxidation, Biomolecules, 4, pp. 980-993.

22. Żołnierczyk Anna K. , Baczyńska Dagmara, Potaniec Bartłomiej, Kozłowska Joanna, Grabarczyk Małgorzata, Woźniak Edyta, Anioł Mirosław (2017), Antiproliferative and antioxidant activity of xanthohumol acyl derivatives, Medicinal Chemistry Research, 26(8), pp. 1764-1771.

23. Yang M., Li N., Li F., Zhu Q., Liu X., Han Q., Wang Y., Chen Y., Zeng X., Yi L., Zhang P., Yang C., Liu Z. (2013), Xanthohumol, a main prenylated chalcone from hops, reduces liver damage and modulates oxidative reaction and apoptosis in hepatitis C virus infected Tupaia belangeri, Int Immunopharmacol, 16, pp. 466-474.

24. Stevens J.F., Page J.E. (2004), Xanthohumol and related prenylflavonoids from hops and beer: to your good health!, Phytochemistry, 65(1317), p. 1330.

25. Protsenko Lidiya, Litvynchuk Svitlana (2015), Competitiveness of Ukrainian pellet hops production, Ukrainian Journal of Food Science, 3(1), pp. 51-59.

26. Protsenko Lidiya, Grynuk Tetiana, Litvynchuk Svitlana (2014), Influence of the constituent alpha acids of Ukrainian varieties of hops and hop preparations on quality indicators of mash and beer, Ukrainian food journal, 3(3), pp. 389-396.

27. McCullough M.P., Volpe R. (2017), Beer and the U.S. Dietary Guidelines: What is Healthful Consumption? Choices. Quarter 3, Available at: http://www.choicesmagazine.org/choices-magazine/theme-articles/beer-policy-and-achanging-global-market/can-beer-consumption-be-part-of-a-healthy-diet.

28. Ahalitika - EBC (1987), European Brebery Convention, Fourth edition.

29. Jaskula B., Goiris K., De Rouck G., Aerts G. and De Cooman, L. (2007), Enhanced quantitative extraction and HPLC determination of hop and beer bitter acids, $J$. Inst.Brew., 113(4), pp. 381-390. 